\title{
PDLLA honeycomb-like scaffolds with a high loading of superhydrophilic graphene/multi-walled carbon nanotubes promote osteoblast in vitro functions and guided in vivo bone regeneration
}

\author{
Edmundo Silva a , Luana Marotta Reis de Vasconcellos ${ }^{\text {b,1 }}$, Bruno V.M. Rodrigues ${ }^{\text {a,c,1 }}$, Danilo Martins dos Santos ${ }^{\mathrm{d}}$, \\ Sergio P. Campana-Filho ${ }^{\mathrm{d}}$, Fernanda Roberta Marciano ${ }^{\mathrm{a}, \mathrm{a}, \mathrm{e}, \mathrm{f}}$, Thomas J. Webster ${ }^{\mathrm{f}}$, Anderson Oliveira Lobo ${ }^{\mathrm{a}, \mathrm{c}, \mathrm{e}, \mathrm{f}, \mathrm{\prime}}$ \\ a Laboratory of Biomedical Nanotechnology, University of Vale do Paraiba, Av. Shishima Hifumi 2911, Sao Jose dos Campos 12224-000, São Paulo, Brazil

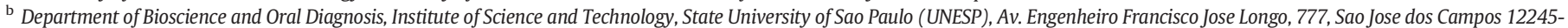 \\ 000, SP, Brazil \\ ${ }^{c}$ Laboratory of Biomedical Nanotechnology, Biomedical Engineering Innovation Center, Universidade Brasil, Rua Carolina Fonseca 235, 08230-030, São Paulo, Brazil \\ d Chemistry Institute of Sao Carlos, University of Sao Paulo, Av. Trabalhador Sao-Carlense, 400, 13566-590 Sao Carlos, SP, Brazil \\ e Department of Medicine, Biomaterials Innovation Research Center, Brigham and Women's Hospital, Harvard Medical School, Cambridge, MA 02139, USA \\ ${ }^{\mathrm{f}}$ Department of Chemical Engineering, Northeastern University, Boston, MA 02115, USA
}

\section{A R T I C L E I N F O}

\section{Article history:}

Received 29 July 2016

Received in revised form 24 October 2016

Accepted 21 November 2016

Available online 23 November 2016

\section{Keywords:}

Poly (D, L-lactic acid)

Multi-walled carbon nanotubes

Graphene oxide

Alkaline phosphatase

In vivo evaluation

Orthopedics

\begin{abstract}
A B S T R A C T
Herein, we developed honeycomb-like scaffolds by combining poly (D, L-lactic acid) (PDLLA) with a high amount of graphene/multi-walled carbon nanotube oxides (MWCNTO-GO, 50\% w/w). From pristine multi-walled carbon nanotubes (MWCNT) powders, we produced MWCNTO-GO via oxygen plasma etching (OPE), which promoted their exfoliation and oxidation. Initially, we evaluated PDLLA and PDLLA/MWCNTO-GO scaffolds for tensile strength tests, cell adhesion and cell viability (with osteoblast-like MG-63 cells), alkaline phosphatase (ALP, a marker of osteoblast differentiation) activity and mineralized nodule formation. In vivo tests were carried out using PDLLA and PDLLA/MWCNTO-GO scaffolds as fillers for critical defects in the tibia of rats. MWCNTO-GO loading was responsible for decreasing the tensile strength and elongation-at-break of PDLLA scaffolds, although the high mechanical performance observed ( $600 \mathrm{MPa})$ assures their application in bone tissue regeneration. In vitro results showed that the scaffolds were not cytotoxic and allowed for osteoblast-like cell interactions and the formation of mineralized matrix nodules. Furthermore, MG-63 cells grown on PDLLA/MWCNTO-GO significantly enhanced osteoblast ALP activity compared to controls (cells alone), while the PDLLA group showed similar ALP activity when compared to controls and PDLLA/MWCNTO-GO. Most impressively, in vivo tests suggested that compared to PDLLA scaffolds, PDLLA/MWCNTO-GO had a superior influence on bone cell activity, promoting greater new bone formation. In summary, the results of this study highlighted that this novel scaffold (MWCNTO-GO, $50 \% \mathrm{w} / \mathrm{w}$ ) is a promising alternative for bone tissue regeneration and, thus, should be further studied.
\end{abstract}

(c) 2016 Elsevier B.V. All rights reserved.

\section{Introduction}

In the context of the biomedical field, poly (lactic acid) (PLA), a wellknown aliphatic polyester, has been strongly highlighted over the years due to its outstanding properties over other commonly used polymers [1-3]. PLA is a biocompatible and biodegradable polymer, which displays easy processability and renewability $[1,3]$. Since 1970 , the U.S.

\footnotetext{
* Corresponding author at: Department of Medicine, Biomaterials Innovation Research Center, Brigham and Women's Hospital, Harvard Medical School, Cambridge, MA 02139, USA.

E-mail addresses: aolobo@pq.cnpq.br, lobo.aol@gmail.com (A.O. Lobo).

1 These authors contributed equally.
}

Food and Drug Administration (FDA) has approved this polyester as a raw material for the manufacturing of a wide range of products, allowing for their contact with biological human fluids.

Four distinct and chiral macromolecules can be prepared from the two isomers of lactic acid, namely L-lactic and D-lactic acids (Fig. 1a). Among the four chiral macromolecules of PLA, PLLA [poly (L-lactic acid), Fig. 1b] [4,5] and PDLLA [poly (D, L-lactic acid), Fig. 1d] [6-8] have received special attention for biomedical applications due to their promising properties. Nevertheless, due to the amorphous nature of PDLLA, this polymer presents a faster and more controllable in vivo degradation profile than PLLA, which is typically semicrystalline [9, 10]. Xiao et al. had reported that the half-life of PDLLA (at $37^{\circ} \mathrm{C}$ and in normal saline) was around 2-3 months, while for PDLA and PLLA, the half-life increases to 4-6 months [11]. 

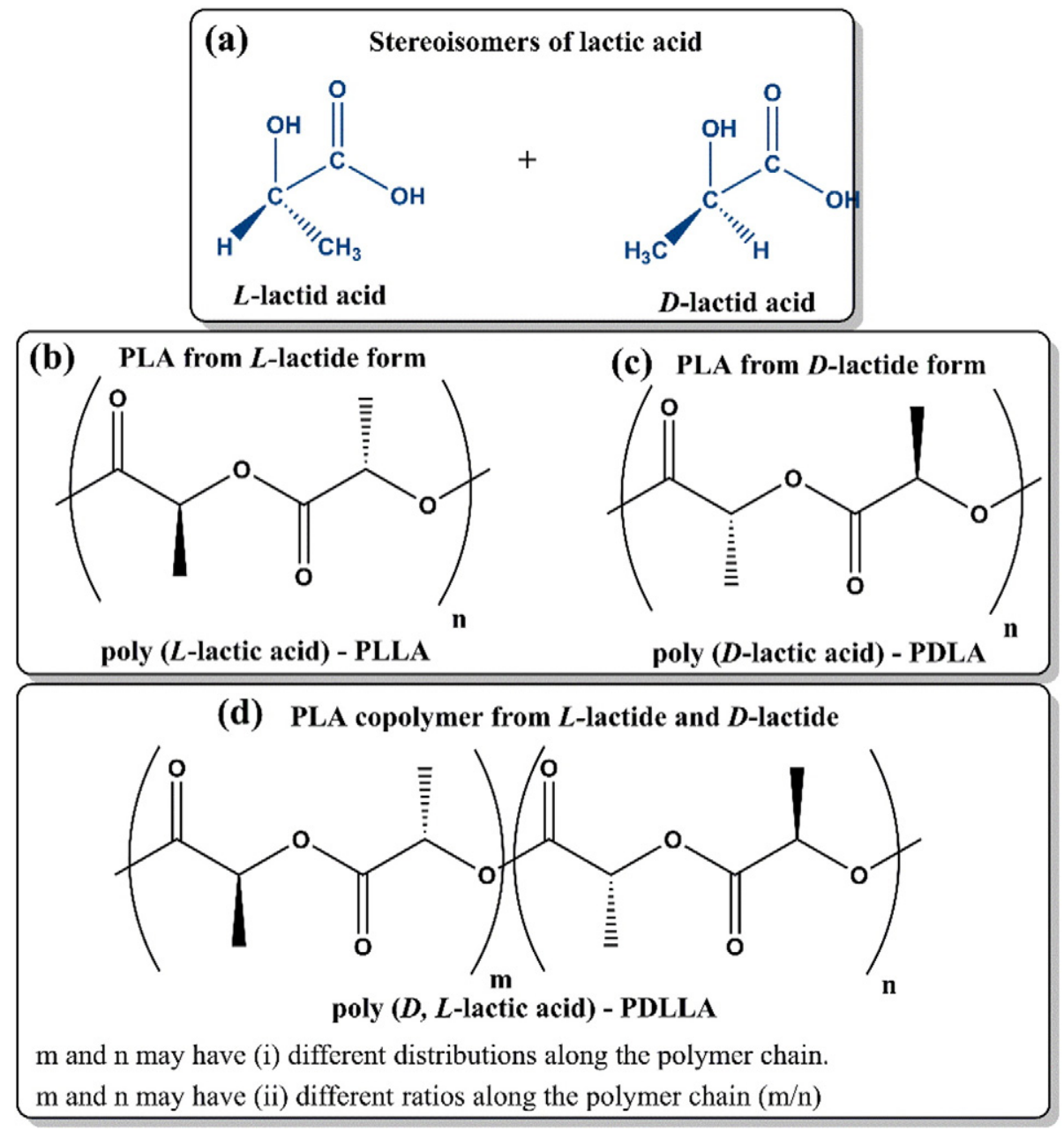

Fig. 1. Chemical structures of (a) the stereoisomers of lactic acid, (b) poly (L-lactic acid), (c) poly (D-lactic acid) and (d) poly (D, L-lactic acid).

In this context, several researchers have been studied the in vitro and in vivo degradation of PDLLA, establishing that the co-products generated from its degradation are natural metabolites that are further eliminated by the human organism [11,12]. At the end, the final degradation of PLA generates essentially $\mathrm{CO}_{2}$ and $\mathrm{H}_{2} \mathrm{O}$, both neither toxic nor carcinogenic $[11,12]$. For this particular reason, there has been extensive research on the use of PDLLA in fields such as drug delivery and tissue engineering [6-8,13,14].

Frequently, conventional polymers, such as PLA, do not meet the requirements for both surface and bulk properties for application in or as biomaterials. In this context, surface modification of known materials, which already have a proven biofunctionality, is a key strategy for producing novel clinically applicable biomaterials. Conversely, if a polymer surface does not meet the suitable properties for a target application, mostly undesired surface events may occur. In this context, the modification of polymeric surfaces using carbon nanotubes (CNT) has been demonstrated to be an excellent approach to achieve the desired physico-chemical, mechanical and biological properties [15-17]. Moreover, the use of plasma-functionalized CNT has been greatly highlighted as a feasible way to increase the oxygen functionalities, such as $-\mathrm{C}=\mathrm{O}-\mathrm{OH},-\mathrm{OH},-\mathrm{C}=\mathrm{O}$ and $-\mathrm{C}-\mathrm{O}$; therefore, a significant increase in the polymer matrix-CNT adhesion interface is achieved when plasma-modified CNT are used instead of pristine-CNT $[10,17,18]$.

In recent work [6], we reported for the first time, the preparation of PDLLA scaffolds with such a high loading of a superhydrophilic graphene/multi-walled CNT oxides (MWCNTO-GO, 50/50, w/w, produced by oxygen-plasma functionalization) and we performed a wide range of characterizations, including thermal, electrochemical and in vitro studies. Our main results indicated: (i) a notable increase in the conductivity of PDLLA after MWCNTO-GO loading ( 5 orders of magnitude); (ii) a reduction in PDLLA hydrophobicity after MWCNTO-GO incorporation (advancing contact angle decreasing from 68 to $46^{\circ}$ ); (iii) PDLLA/MWCNTO-GO scaffolds promoted significant cellular adhesion with no cytotoxicity effect using L-929 mouse fibroblasts; and (iv) reduced bactericidal activity.

In contribution to all of the aforementioned properties, we also showed in previous work that after high loading of MWCNTO-GO in a PDLLA matrix, our novel nanocomposite demonstrated enhanced bone bioactivity (after submerging in simulated body fluid for 14 days) compared to controls (plain PDLLA). The honeycomb-like surface of PDLLA/ MWCNTO-GO may have favored initial apatite nucleation, which was further evidenced by the precipitation of a compact layer of globular hydroxyapatite and calcite crystals (as evaluated by SEM). To support our conclusions, FTIR results identified a higher presence of carbonate vibrational modes, as well as being more intense, in the PDLLA/MWCNTO-GO scaffolds; also, the carbonate/phosphate area ratio increased from 0.209 to 3.356 after MWCNTO-GO loading, pointing out the pronounced bone bioactivity due to nanomaterial incorporation. All of these results demonstrated the high potential of this novel scaffold for numerous biomedical applications, which has motivated a further investigation on its in vivo potential for bone regeneration [6].

Herein, we present the production and in vitro as well as in vivo characterization of a recent novel porous honeycomb-like scaffold based on PDLLA loaded with high amounts of MWCNTO-GO (50/50 w/w) intended for bone regeneration. MWCNTO-GO were produced via oxygen plasma treatment on pristine MWCNT, which promoted its 


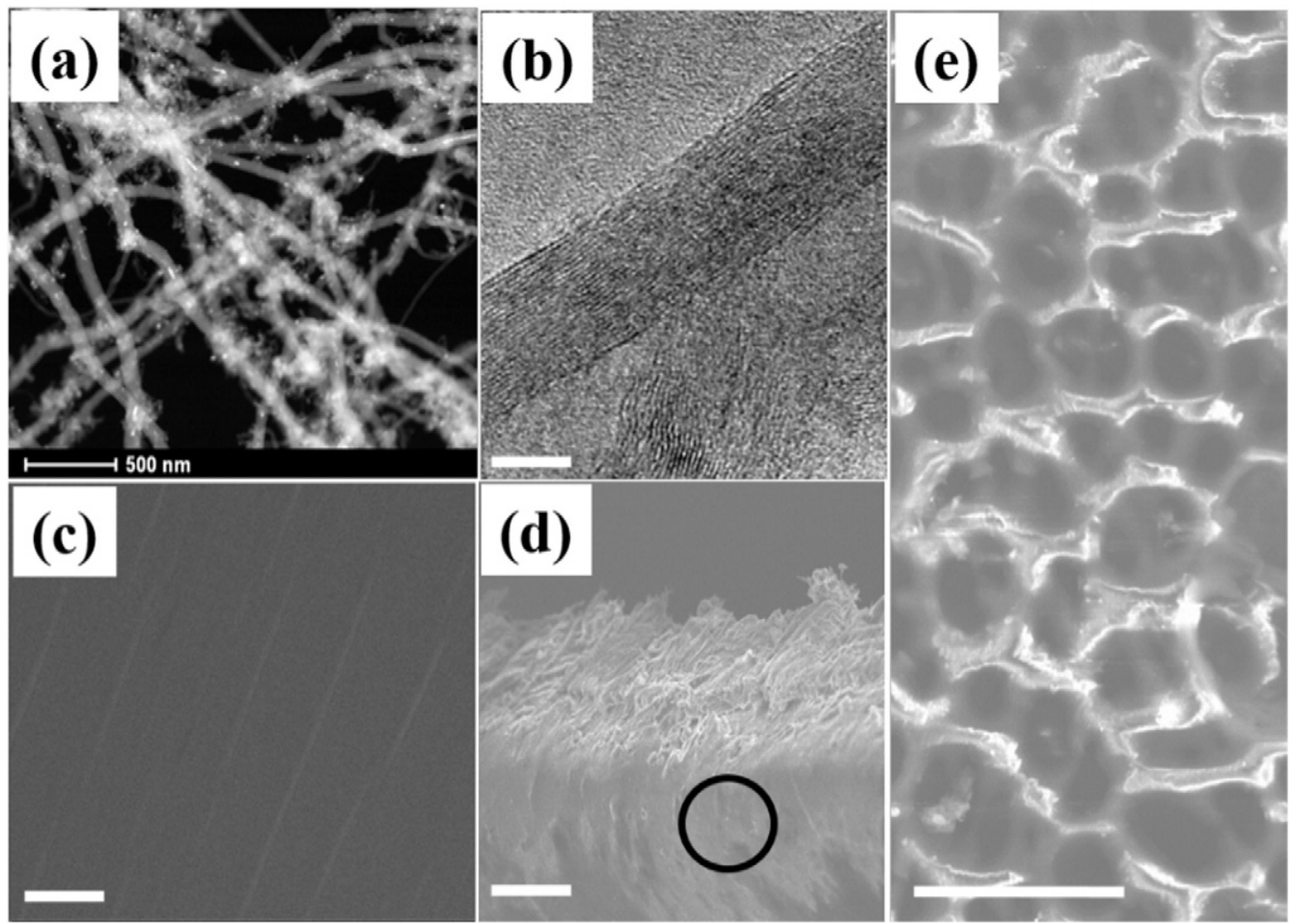

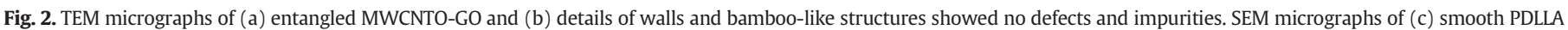

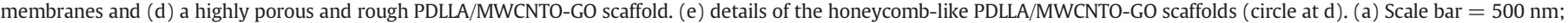
(b, c, d, e) Scale bars $=20 \mu \mathrm{m}$.

exfoliation and oxidation, further generating a superhydrophilic material that is highly dispersible in liquid medium. These novel PDLLA/ MWCNTO-GO scaffolds enhanced alkaline phosphatase (ALP) activity from osteoblast-like MG63 cells when compared to PDLLA. This could be attributed to the roughness and macro-porosity exhibited by the PDLLA/MWCNTO-GO scaffolds. We also observed that all scaffolds stimulated osteoblast differentiation due to mineral deposits formed by osteoblasts on the PDLLA/MWCNTO-GO scaffolds. Interestingly, PDLLA/ MWCNT-GO scaffolds promoted lamellar bone formation after 2 weeks of implantation. All of these characteristics highlight and motivate the use of these novel nanobiomaterials for numerous orthopedics tissue engineering applications.

\section{Experimental}

All chemicals used in this work were purchased from Sigma Aldrich ${ }^{\circledR}$, unless another source is mentioned. Puracbiochem (Netherlands) graciously provided us the PDLLA pellets used in this work [FDA approved, PLD 9620 - copolymer of L-lactide and D-lactide $(96 / 04)]$

\subsection{MWCNT preparation and further functionalization of MWCNTO-GO}

First, we synthetized the MWCNT followed by purification, functionalization and exfoliation to generate MWCNTO-GO. Briefly, MWCNT were prepared using a mixture of camphor (90\% w) and ferrocene in a thermal chemical vapor deposition furnace at $850{ }^{\circ} \mathrm{C}$ for up to $1 \mathrm{~h}$ [19]. Next, we performed the purification using $10 \mathrm{M}$ hydrochloric acid for up to $1 \mathrm{~h}$ at $100{ }^{\circ} \mathrm{C}$ [19]. To generate MWCNTO-GO, the incorporation of oxygen-containing groups and simultaneous exfoliation of MWCNT were carried out in a pulsed direct-current plasma reactor with an oxygen flow rate of $1 \mathrm{sccm}$, at a pressure of $150 \mathrm{mTorr}$ $-700 \mathrm{~V}$, and pulse frequency of $20 \mathrm{kHz}$ [19].

High resolution transmission electron microscopy (HRTEM, FEI Tecnai $G^{2}$ F20 microscope) was performed to identify the walls, bamboo-like structures and presence of probable contaminants inside the MWCNT-GO tubes. For this, the MWCNTO-GO powders were dispersed in $50 \mathrm{~mL}$ of water under sonication (Vibracell Sonics, $500 \mathrm{~W}$, $20 \mathrm{kHz}$, probe amplitude adjusted to $40 \%$ ) for $15 \mathrm{~min}$, and then deposited on a copper grid (300 mesh).

\subsection{Preparation of PDLLA and PDLLA/MWNCTO-GO scaffolds}

Neat PDLLA (control scaffolds) was prepared by dissolving the polymer pellets at $10 \% \mathrm{w} / \mathrm{v}$ in chloroform. For the PDLLA/MWCNTO-GO scaffolds, we dispersed MWCNTO-GO powder $(50 \% \mathrm{w} / \mathrm{w})$ in a PDLLA solution $(10 \% \mathrm{w} / \mathrm{v}$ in chloroform) under ultrasound irradiation $\left(1200 \mathrm{~J} \mathrm{~mL}^{-1}, 57 \mathrm{~W}\right)$ at $40{ }^{\circ} \mathrm{C}$ for $120 \mathrm{~min}$. Both solutions were dropped into square molds ( $5 \mathrm{~mm} \times 5 \mathrm{~mm} \times 1 \mathrm{~mm}$ ) and dried for $12 \mathrm{~h}$ at room

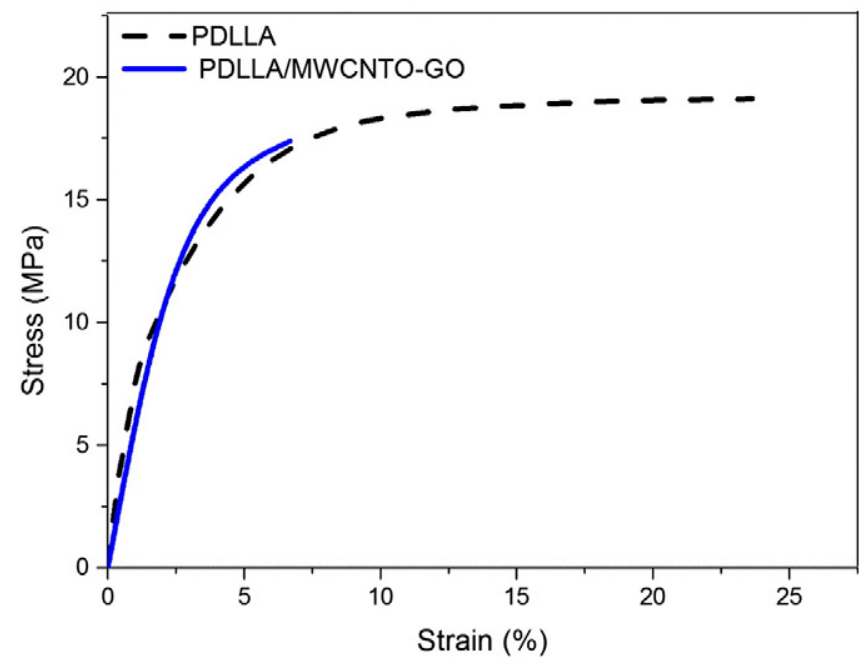

Fig. 3. Stress-strain curves of PDLLA and PDLLA/MWCNTO-GO scaffolds. 
Table 1

Tensile properties of PDLLA and PDLLA/MWCNTO-GO mats.

\begin{tabular}{llll}
\hline Sample $^{*}$ & $\begin{array}{l}\text { Elastic modulus } \\
(\mathrm{MPa})\end{array}$ & $\begin{array}{l}\text { Tensile strength } \\
(\mathrm{MPa})\end{array}$ & $\begin{array}{l}\text { Elongation at } \\
\text { break }(\%)\end{array}$ \\
\hline PDLLA & $679.1 \pm 88.9^{\mathrm{a}}$ & $19.6 \pm 1.2^{\mathrm{b}}$ & $22.3 \pm 3.8^{\mathrm{d}}$ \\
PDLLA/MWCNTO-GO & $597.3 \pm 106.4^{\mathrm{a}}$ & $16.0 \pm 2.0^{\mathrm{c}}$ & $6.3 \pm 0.5^{\mathrm{e}}$ \\
\hline
\end{tabular}

* Means followed by the same letter in the columns do not differ by a Tukey's test at $5 \%$ probability.

temperature. After drying, the scaffolds were functionalized using oxygen plasma to enhance the wettability of scaffolds [20].

A Field Emission Scanning Electronic Microscope (FE-SEM, FEI Inspect F50), operated at $10 \mathrm{kV}$, was used to characterize the morphology of scaffolds. Before analysis, all samples were previously coated with a thin gold layer $(\sim 10 \mathrm{~nm})$ in order to improve micrograph acquisition. Parameters such as porosity and pore size were evaluated using ImageJ.

\subsection{Mechanical properties}

A Dynamic Mechanical Analyzer (DMA Q800, TA Instruments) was used in tension mode to perform mechanical tests of the scaffolds according to ASTM D 882-12 with few modifications. Specimens $(15 \mathrm{~mm} \times 6.4 \mathrm{~mm} \times 0.15 \mathrm{~mm})$ were cut from each scaffold and preconditioned at $25^{\circ} \mathrm{C}$ and $50 \%$ of relative humidity for $24 \mathrm{~h}$ before tests. The initial distance between the grips was set at $5 \mathrm{~mm}$ and the measurements were carried out at $25{ }^{\circ} \mathrm{C}$ with a ramp strength of $1 \mathrm{~N} \mathrm{~min}{ }^{-1}$ up to $18 \mathrm{~N}$ using a preload strength of $0.01 \mathrm{~N}$. Five scaffolds were tested for each group and the elastic modulus (MPa), tensile strength (MPa) and elongation-at-break (\%) were determined.

\subsection{In vitro evaluation - cell culture}

Initially, scaffolds were placed into well plates and sterilized in absolute ethanol followed by UV exposure for $3 \mathrm{~h}$. Before cell culture, the scaffolds were immersed for $24 \mathrm{~h}$ in $1 \mathrm{~mL}$ of Dulbecco's Modified Eagle Medium (DMEM). All in vitro tests were carried out using MG63 osteoblast-like cells (Cambrex Bio Science Walkersville, Inc.) and repeated 3 times to ensure reproducibility. Cells were cultured in a Modified Eagle's Medium (Gibco-Life Technologies, NY, USA) containing 10\% fetal bovine serum (Gibco), $100 \mathrm{mg} \mathrm{mL}^{-1}$ streptomycin (Gibco), and $100 \mathrm{mg} \mathrm{mL}^{-1}$ penicillin (Gibco) at $37^{\circ} \mathrm{C}$ in a humidified atmosphere of $5 \%(\mathrm{v} / \mathrm{v}) \mathrm{CO}_{2}$. Then, MG63 cells were seeded at a density of $2 \times 10^{4}$ cells/well in 24-well plates on the top of each scaffold (PDLLA and PDLLA/MWCNTO-GO). Culture plates (TCP) were used as controls for all in vitro analysis.

The 3-[4,5-dimethylthiazol-2-yl]-2,5- diphenyltetrazolium bromide (MTT), alkaline phosphatase activity (ALP) and quantification of matriz mineral production assays were used to evaluate the cell viability, osteoblastic differentiation and bone-like nodule formation.

\subsubsection{MTT assay}

After 7 days of cell culture, the supernatants extracted from each group were placed in culture medium containing the MTT solution and then were incubated in a humidified atmosphere at $37^{\circ} \mathrm{C}$, for $4 \mathrm{~h}$, to form purple formazan crystals [21]. Next, the wells were washed with $\mathrm{PBS}$ and $1 \mathrm{~mL}$ of acidified isopropanol $(0.04 \mathrm{~N} \mathrm{HCl}$ in isopropanol) was added to each well to solubilize the formazan crystals. Then, each solution was transferred to a 96-well plate and colorimetric analysis was performed for each well using an EL808IU spectrophotometer ( $570 \mathrm{~nm}$, Biotek Instruments, Winooski, VT, USA). The data were expressed as OD and values were represented as the average $(n=3)$.

\subsubsection{Alkaline phosphatase activity}

ALP activity was evaluated after cell incubation for 3 days by thymolphthalein monophosphate substrate hydrolysis (Labtest Diagnóstica, Belo Horizonte, BR) in accordance with the manufacturer's recommendations. All procedures were performed as described by Rodrigues, et al. [18]. The ALP activity was expressed as OD and the values represented as mean \pm standard deviation $(n=3)$.

\subsubsection{Mineralized bone-like nodule formation}

PDLLA and PDLLA/MWCNTO-GO scaffolds were allowed to contact MG63 cells for 14 days (in a 96-well plate). Next, the wells were washed three times using Hank's solution at $37^{\circ} \mathrm{C}$, and fixed with $70 \%$ ethanol, for $1 \mathrm{~h}$, at $4{ }^{\circ} \mathrm{C}$. After fixation, the wells were washed twice with PBS and stained for $1 \mathrm{~h}$ with $2 \%$ Alizarin red ( $\mathrm{pH} 4.2$ ). After the incubation, the wells were washed with deionized water. The newly-formed bone-like nodules on the scaffolds were stained and a phase contrast microscopy (Model Axiovert 40C, Carl Zeiss Microscopy GmbH, Jena, Germany) was used to capture the images.

\subsection{In vivo evaluation}

In vivo studies were carried out using four adult male rats weighing $300 \mathrm{~g}$ each. The rats were supplied by the Animal Center of Sao Jose dos Campos School of Dentistry, which were kept in cages, fed with commercial pet food (Guabi Nutrilabor) and water ad libitum. This study was approved by the Ethics in Research Committee of UNICAMP, Campinas, Brazil (ZIP:3253-1/Brazil).

Before surgery, PDLLA and PDLLA/MWCNTO-GO scaffolds were sterilized using ethanol (70\%), followed by 2 h of UV irradiation. All surgical procedures were in agreement with the Ethical Principles for Animal Research established by the National Council of Animal Experimentation Control (CONCEA). The rats were anesthetized by applying an intramuscular injection of xylazine chloride $(0.04 \mathrm{~mL} / 100 \mathrm{~g}$ body weight, Anasedan, Bayer, SP, Brazil) associated with Ketamine chloride (0.08 mL/100 g body weight, Dopalen, Agrbands do Brazil Ltda, SP, Brazil).

After skin shaving and antiseptic treatment of the tibia, an incision was made in the skin and muscle from the medium third of the left and right tibias. The monocortical defects were initially made using a

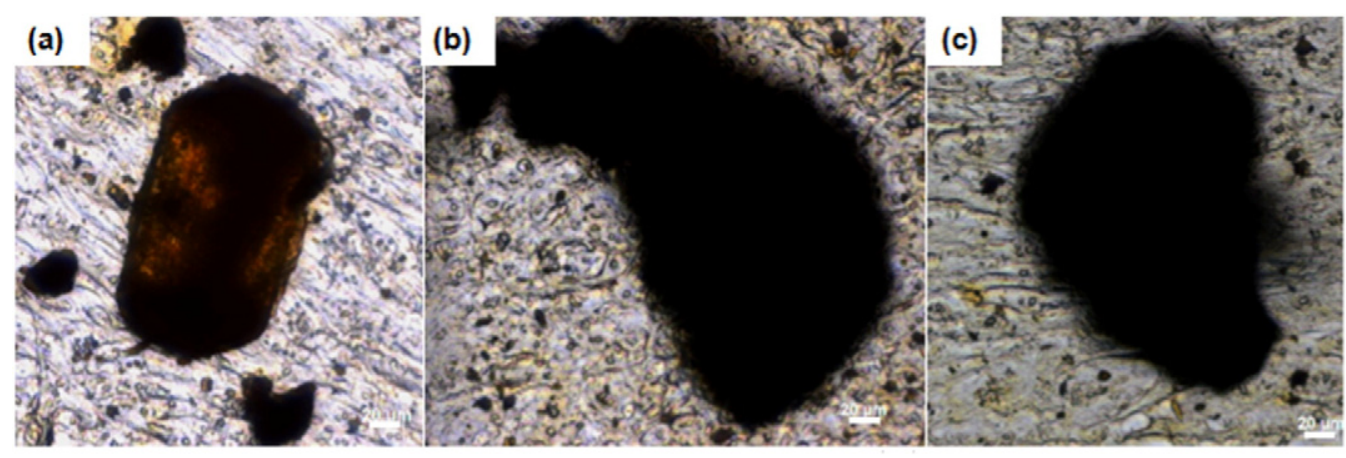

Fig. 4. Osteoblast-like MG63 cells formed mineralized nodules after 14 days. (a) Control group, (b) PDLLA, and (c) PDLLA/MWCNTO-GO scaffolds. 

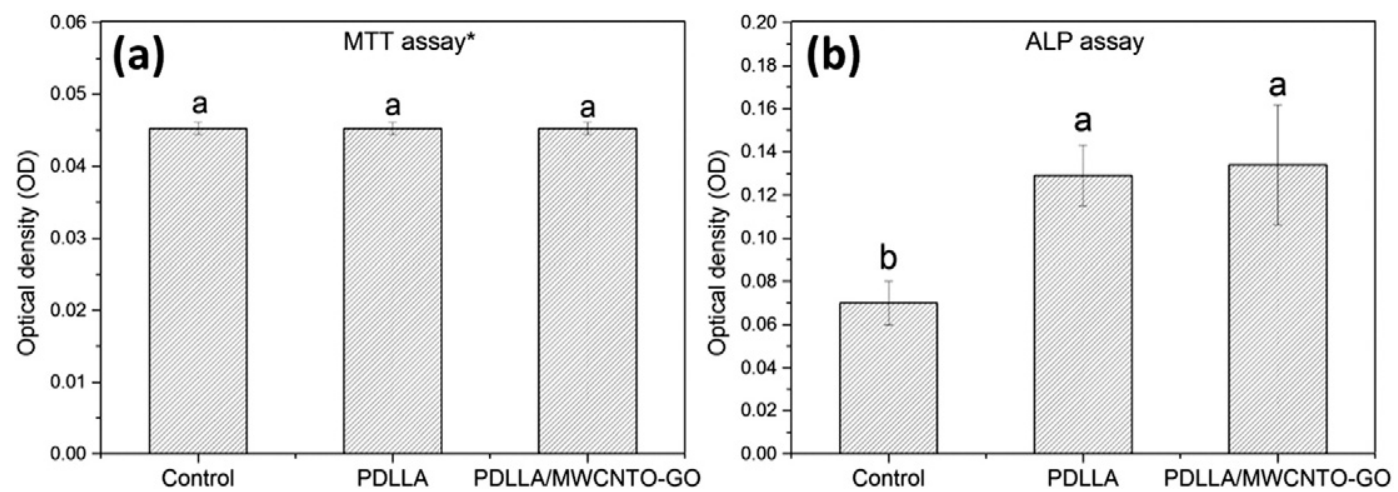

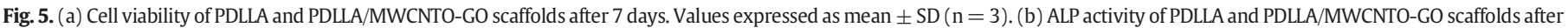
3 days. *Values were expressed as mean \pm SD $(n=3)$. Means followed by the same letter do not differ by the Tukey's test at $5 \%$ probability.

Ø2.0 mm bone cutter (code 795.203 Titanium Fix®, São José dos Campos, SP, Brazil), followed by Ø2.5 mm, Ø3.0 mm and Ø3.5 mm helical cutters (code 795.121, Titanium Fix ${ }^{\circ}$, Sao Jose dos Campos, SP, Brazil). An electrical motor was used at $1600 \mathrm{rpm}$ under constant irrigation with abundant $0.9 \%$ sodium chloride solution. Sterilized mini-rolls of scaffolds ( $3.5 \mathrm{~mm}$ diameter) matching each group were placed into the defects. As standardization, for all animals, PDLLA/MWCNTO-GO scaffolds filled a defect located at the left tibia while PDLLA scaffolds filled a defect located at the right tibia. The sites were sutured using no. 4-0 silk thread (Ethicon/Johnson \& Johnson, São José dos Campos, $\mathrm{SP}$, Brasil) and swabbed with iodate alcohol. The rats were inspected daily for clinical signs of complications or adverse reactions. The rats
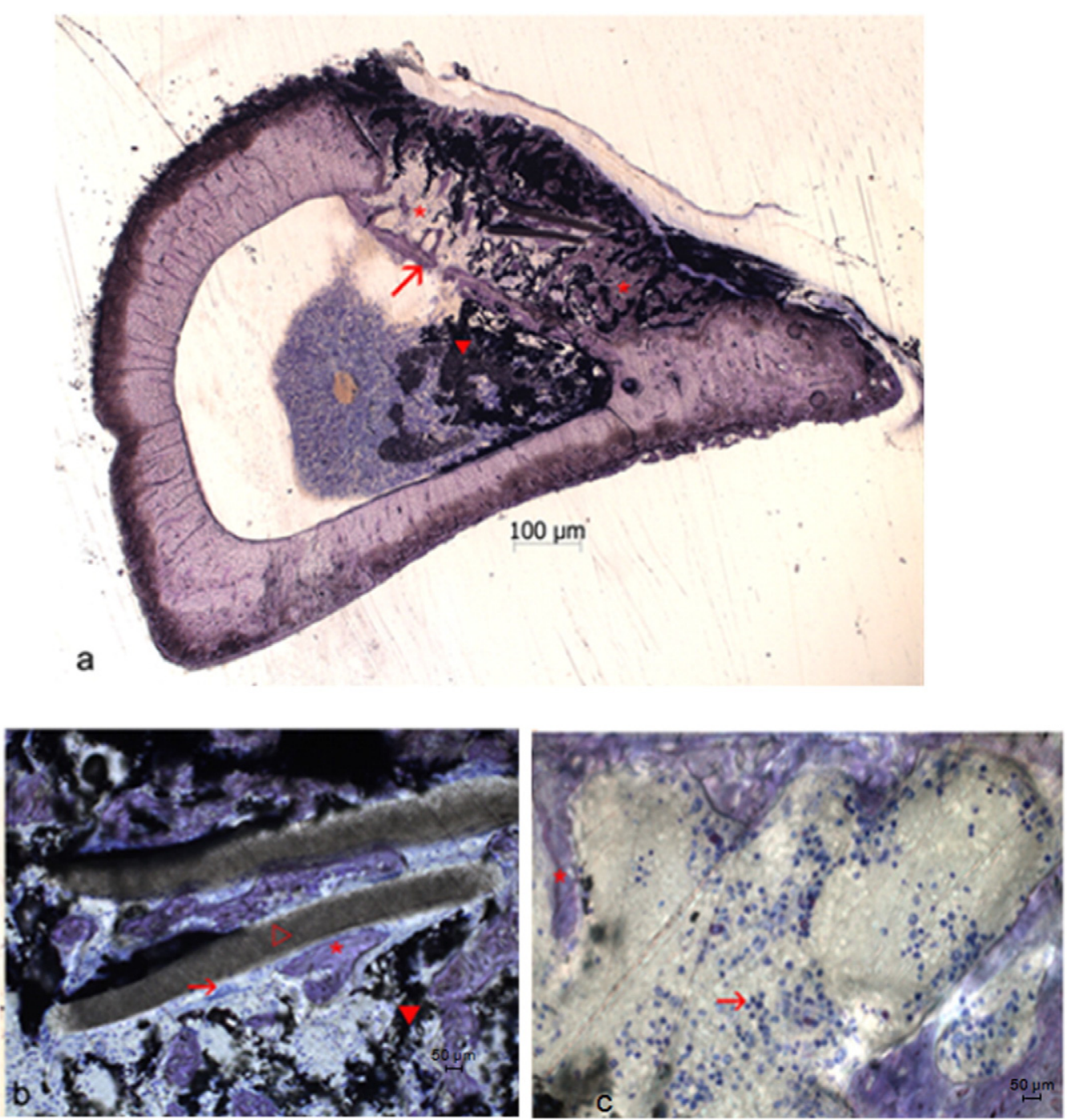

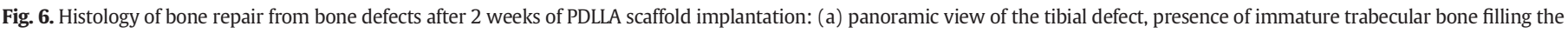

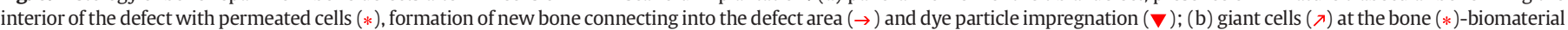
$(\triangleright)$ interface showing intimate contact between them, and dye particle impregnation $(\nabla)$; and (c) discrete inflammatory response infiltrates $(\rightarrow)$ new bone trabeculae $(*)$. 

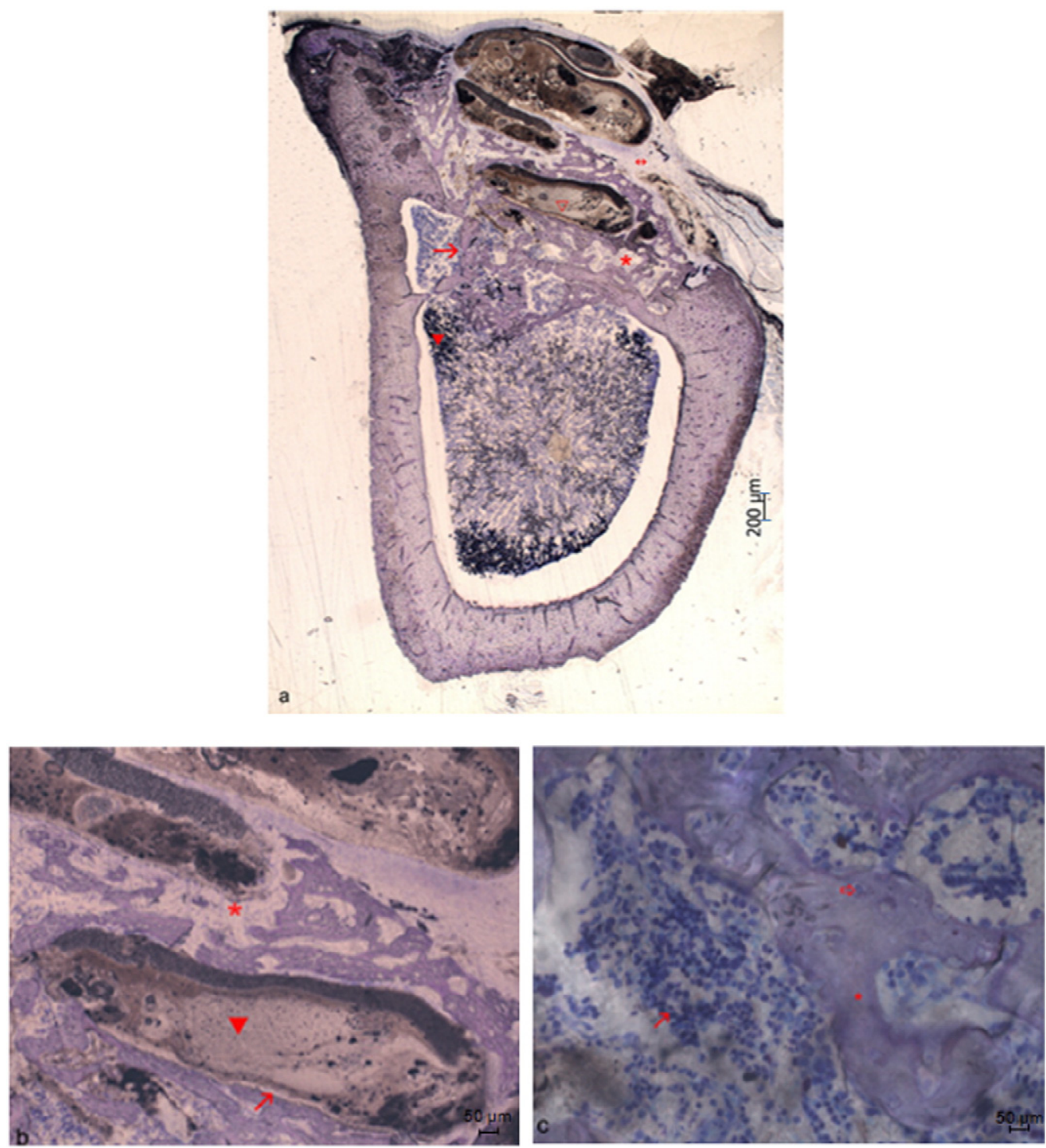

Fig. 7. Histology of bone repair from the bone defect after 2 weeks of PDLLA/MWCNTO-GO scaffold implantation: (a) panoramic view of the defect in the tibia, presence of immature trabecular bone filling the interior of the defect $(*)$ and bone migration into the tibia marrow bone $(\rightarrow)$, and the connective tissue above of defect presented moderate fibroblast numbers and many collagen fibers $(\Theta)$, dye particles impregnating the tissue area $(\boldsymbol{\nabla})$, and the biomaterial $(\triangleright)$; (b) the bone-biomaterial interface $(\boldsymbol{\lambda})$ showing intimate contact between bone and scaffold fragments $(\boldsymbol{\nabla})$, also it was observed around the presence of cells $(*)$ and well-organized bone trabeculae $(*)$; and (c) discrete inflammatory infiltrates $(\lambda)$ permeating new bone trabeculae $(*)$ exhibiting osteocytes $(\Leftrightarrow)$

(A) PDLLA

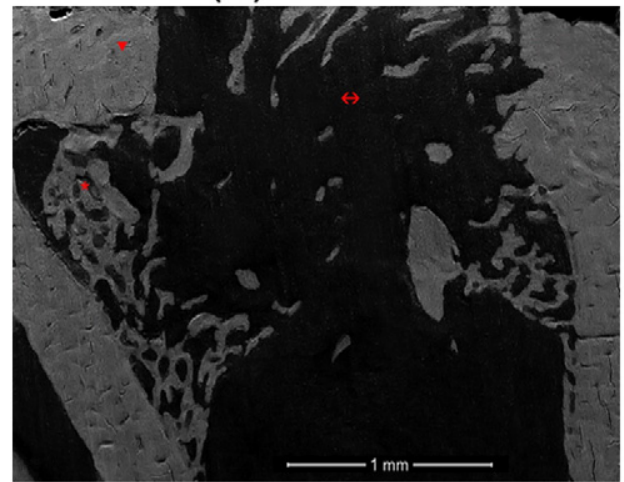

\section{(B) PDLLA/MWCNTO-GO}

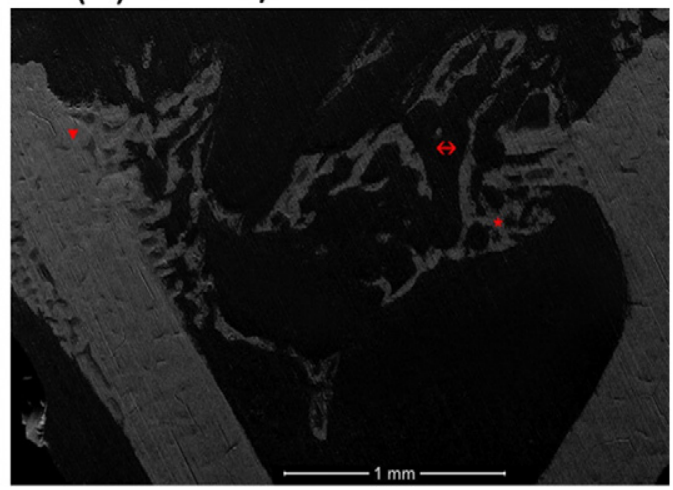

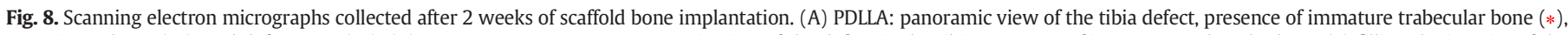

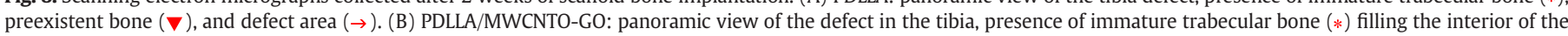
defect $(\rightarrow)$ and preexistent bone $(\boldsymbol{\nabla})$. 
were euthanized using an anesthetic overdose administered intramuscularly 2 weeks after surgery.

For histological analysis, the surgical sites were fixed in 10\% neutral buffered formalin. Specimens were then dehydrated for 12 days with a graded series of alcohols. Tissue sections were stained with Toluidine blue. SEM micrographs were also acquired for the same slices to provide more details about the implantation sections.

\subsection{Statistical analysis}

Results were expressed as mean \pm standard deviation. Statistical analyses were carried out using the open-source statistical programming language R (v.3.3.0). Data were tested for normality and homogeneity of variances using the Shapiro - Wilks test of normality and an F test. Statistical significance between different treatments was determined using analysis of variance (ANOVA) and a post-hoc Tukey's test; $p$ value $\leq 0.05$ was used to determine significant differences.

\section{Results and discussion}

\subsection{Material characterization}

Fig. 2a shows the typical morphologies of MWCNTO-GO. We noticed that MWCNTO-GO showed entangled structures containing Fe nanoparticles inside the tubes (from the catalyst, white dots). Fig. 2b shows that MWCNTO-GO had around of 50 walls (visual count) and presented bamboo-like structures. Fig. 2c provided evidence that the raw PDLLA membrane had a smooth and homogeneous surface, whereas the MWCNTO-GO loading (Fig. 2d) promoted roughness and porosity on the scaffold's surface. Fig. 2e shows that the PDLLA/MWCNTO-GO presented honeycomb-like structures with high macro-porosity and roughness (details collected from the cross-section of Fig. 2d), both desirable characteristics to promote guided bone tissue regeneration [22].

It is well-known that the mechanical properties of a biomaterial play a great role in bone tissue engineering. Ideally, a biomaterial must support the bone tissue regeneration at the site of implantation and maintain sufficient integrity during both in vitro and in vivo cell growth. Tensile strength of the membranes was determined through their derived stress-strain curves (Fig. 3). The elastic modulus, elongation-at break and tensile strength of the scaffolds were obtained, and the corresponding data are displayed in Table 1. Clearly, after MWCNTO-GO loading, the values of tensile strength and the elongation-at-break decreased, whereas the values of elastic modulus presented no significant difference $(p \geq 0.05)$. We can attribute this behavior to the weak interactions between the MWCNTO-GO and the polymeric molecular chains. Thus, the polymer chains would not be able to transfer the load to the MWCNTO-GO, resulting in decreased values of tensile strength. Moreover, we can expect that MWCNTO-GO agglomeration took part in some regions in the polymer matrix due to the decrease in the elongation-at-break values. Similarly, Saligheh et al. [23] reported that after addition of a high amount of MWCNT into poly (butylene terephthalate) (PBT) matrices ocurred a decrease in tensile strength of electrospun membranes.

\subsection{Biological assays}

We performed several in vitro and in vivo assays to evaluate osteoblast functions and consequently the bone regeneration guiding ability of our produced scaffold. Tipically, a mineral deposition is the last phase of osteoblast differentiation, and alizarin red staining is a common method used to determine calcium deposition in a cellular matrix [8,24-27]. Fig. 4b \& c shows that all scaffolds were able to induce nodule mineralization compared to control groups (Fig. 4a). Nevertheless, we did not observe any statistical differences between PDLLA (Fig. 4b) and PDLLA/MWCNTO-GO (Fig. 4c) scaffolds, but we noticed that both were able to stimulate osteoblast-like MG63 cells to produce more calcified regions than the control (Fig. 4a).

We noted that all scaffolds acted directly at the final stage of osteoblast differentiation, which was evidenced by the mineralization of the extracellular matrix, especially to PDLLA/MWCNTO-GO scaffolds. This result was consistent with previous studies [14]. Fig. 5a shows that all scaffolds were non-cytotoxic compared to controls $(p>0.05)$. Fig. 5b shows the ALP activity of control, PDLLA and PDLLA-MWCNTO-GO composites. Briefly, the scaffolds presented higher ALP activities than the control group. ANOVA one-way analysis confirmed a higher ALP activity (at the level of $p<0.05$ ) between all scaffolds. With time, the Tukey's test confirmed a significant mean difference comparing controls to the PDLLA and PDLLA-MWCNTO-GO composites.

All in vitro results were illustrative and could confirm the great potential of PDLLA/MWCNTO-GO composites as candidate for biomedical applications. As previously described, PDLLA is a biodegradable polymer approved by the FDA. In this context, several techniques have been performed to promote surface modification for improving cellular adhesion and growth in/on polymers approved by FDA. The use of PDLLA as a scaffold for bone regeneration has been already explored in previous work [8,24-26]. However, herein we incorporated a high load of MWCNTO-GO into a PDLLA matrix in order to evaluate in vitro osteoblast-like MG63 cell functions.

Some studies show a positive correlation between the number of viable cells and high ALP activity [8,24-26]. Here, we performed a similar study, but we found a consensus using both assays (Fig. $5 \mathrm{a}$ and $3 \mathrm{~b}$ ). While metabolic activity is a sign of osteoblast differentiation, ALP activity is a major characteristic of osteoblasts and it is regarded as an early marker for osteoblast differentiation [40]. Thus, ALP activity has been largely used to evaluate the development of new biomaterials for guided bone regeneration $[30,36,37]$. Our results indicated that both scaffolds, PDLLA and PDLLA/MWCNTO-GO, could induce osteoblastic differentiation, such as observed in other studies [8,24-26].

We noticed that all scaffolds supported the final stage of osteoblast differentiation. It was evidenced by osteoblast mineralization (Fig. 3b), and also identified by Leal et al. [14]. Several papers have disagreed about the use of MWCNT based materials as scaffolds for cell growth [28-32] due to their superhydrophobicity and, as some have claimed, they may be cytotoxic (possibly due to the incomplete reaction of toxic catalysts used during their synthesis) [33-38]. Conversely, our results show and continue to support studies which highlight the positive use of MWCNT in medicine.

Several papers have been published by our group reporting the use of superhydrophilic MWCNTO-GO as is or in bioscaffolds in contact with different cell lines [39-42]. In all of these studies, we have demonstrated their non-cytotoxicity and tissue regeneration ability using animal models [43]. Recently, we demonstrated that PDLLA membranes with low MWCNTO-GO content accelerated in vivo bone regeneration and induced bone lamellar formation [43]. Herein, we advanced this issue since we conducted in vivo studies with positive biological responses using high amounts of MWCNTO-GO in composites.

Fig. 6 and Fig. 7 show photomicrographs collected from in vivo bone slides after 2 weeks of PDLLA (Fig. 6) and PDLLA/MWCNTO-GO implantations (Fig. 7). Blue toluidine was used to stain the histological sections. After 2 weeks, the defects were mainly filled by new bone trabeculae permeated with cells, exhibiting a thin and delicate aspect and intimate contact with both scaffolds (*, Figs. $6 \& 7$ ). We noticed that the use of PDLLA scaffolds led to reduced bone formation compared to PDLLA/ MWCNTO-GO. This result is clearly attributed to the new bone formation connected by a bridge between the implantation region and the edge of the defect ( $\lambda$, Fig. 6a). Meanwhile, the bone defect filled by the PDLLA/ MWCNTO-GO scaffold promoted lamellar bone formation $(\rightarrow$, Fig. 7a). It is very illustrative and corroborates with the in vitro results, since there was a migration of a new bone tissue into the marrow of the bone tibia, suggesting more effective osteogenesis when PDLLA/MWCNTO-GO scaffolds were used. 
The newly formed bone self-organized due to the presence of osteocytes in lacunae, osteoblasts delineating the trabeculae, and the formation of marrow space. These aspects were observed in both scaffolds (*, Figs. 6c \& 7c). Both photomicrographs showed highly organized bone, Haversian systems, viable cells and no bone necrosis signals (*, Figs. $6 \mathrm{~b} \& 7 \mathrm{~b}$ ). Moreover, in Fig. $6 \mathrm{~b}(\rightarrow)$, we identified giant cells between the bone $(*)$-biomaterial interface $(\triangleright)$. We also observed a discrete inflammatory presence infiltrating into the surgical defect $(\rightarrow$, Fig. $6 \mathrm{c}$ and $\lambda$, Fig. 7c). A connective tissue lightly above the defect with both moderate fibroblast numbers and many collagen fibers were also identified $(\Theta$, Fig. 7a). Likewise, we could identify small particles from the degradation of the scaffolds, especially when the defect was filled with PDLLA ( $\triangleright$, Fig. 6 b and $\nabla$, Fig. 7a). All histological sections showed black dots due to the impregnation of dye particles ( $\Delta$, Figs. 6b \& 7a). This may be attributed to a high affinity between the degraded polymer and MWCNTO-GO nanoparticles with blue toluidine (Figs. 6a \& 7a \& 6b).

Fig. 8 shows the SEM micrographs collected from the same histological slices previously presented (Fig. 6, Fig. 7). Clear differences are noticed between PDLLA (Fig. 8A) and PDLLA/MWCNTO-GO scaffolds (Fig. $8 \mathrm{~B}$ ). The bone formation is more obvious when PDLLA/MWCNTO-GO scaffolds were implanted than other groups. The defect area filled with PDLLA/MWCNTO-GO formed one bridge between the edges of the defect $(\leftrightarrow$, Fig. 8B), whereas the defect area filled with PDLLA continued without bone tissue ( $\leftrightarrow$, Fig. 8A).

\section{Conclusions}

Three-dimensional porous bio-scaffolds were prepared combining PDLLA with exfoliated and oxidized multi-walled carbon nanotubes and graphene oxide (MWCNTO-GO). The MWCNTO-GO powder was highly dispersed in a chloroform/PDLLA solution, allowing for a high concentration $(50 / 50 \mathrm{w} / \mathrm{w})$. Such high concentration led to a honeycomb-like scaffold with pore sizes ranging from 7 to $15 \mu \mathrm{m}$ (in diameter). Mechanical analysis revealed that MWCNTO-GO loading was responsible for decreasing the tensile strength and elongation-atbreak. Despite this, the high mechanical performance of the PDLLA/ MWCNTO-GO scaffolds was still high enough to assure their application in bone tissue regeneration. From the in vitro results, we clearly showed that PDLLA/MWCNTO-GO was cytocompatible and allowed for better in vitro osteogenic differentiation (ALP activity and matrix mineralization) than controls. We showed that the honeycomb-like PDLLA/MWCNTOGO scaffolds induced more lamellar bone formation than smooth PDLLA scaffolds, suggesting multiple potential uses of this scaffold for bone regeneration purposes.

\section{Acknowledgments}

The authors would like to thank the National Council for Scientific and Technological Development (CNPq, 474090/2013-2), São Paulo Research Foundation (FAPESP, 2011/17877-7, 2011/20345-7, 2015/ 09697-0 and 2016/00575-1), Brazilian Innovation Agency (FINEP grant 0113042800 ) and Coordination for the Improvement of Higher Education Personnel (CAPES, 88887.095044/2015-00) for financial support. B. V. M. R. would also like to thank FAPESP for a postdoctoral fellowship (FAPESP, 2015/08523-8). D. M. dos Santos is grateful to CNPq for the PhD fellowship (CNPq, 142002/2014-3)

\section{References}

[1] I. Tawakkal, M.J. Cran, J. Miltz, S.W. Bigger, A review of poly(lactic acid)-based materials for antimicrobial packaging, J. Food Sci. 79 (2014) R1477-R1490.

[2] A.J.R. Lasprilla, G.A.R. Martinez, B.H. Lunelli, A.L. Jardini, R. Maciel, Poly-lactic acid synthesis for application in biomedical devices - a review, Biotechnol. Adv. 30 (2012) 321-328.

[3] K. Hamad, M. Kaseem, H.W. Yang, F. Deri, Y.G. Ko, Properties and medical applications of polylactic acid: a review, Express Polym Lett 9 (2015) 435-455.
[4] L. He, P. Zhao, Q. Han, X. Wang, X. Cai, Y. Shi, L. Zhou, Y. Zhang, W. Xue, Surface modification of poly-l-lactic acid fibrous scaffolds by a molecular-designed multi-walled carbon nanotube multilayer for enhancing cell interactions, Carbon 56 (2013) 224-234.

[5] M.D. Schofer, P.P. Roessler, J. Schaefer, C. Theisen, S. Schlimme, J.T. Heverhagen, M Voelker, R. Dersch, S. Agarwal, S. Fuchs-Winkelmann, J.R. Paletta, Electrospun PLLA nanofiber scaffolds and their use in combination with BMP-2 for reconstruction of bone defects, PLoS One 6 (2011), e25462.

[6] H. Zanin, B.V.M. Rodrigues, W.A. Ribeiro Neto, R.E.S. Bretas, N.S. da Silva, F.R. Marciano, A.O. Lobo, High loading of graphene oxide/multi-walled carbon nanotubes into PDLLA: A route towards the design of osteoconductive, bactericidal and non-immunogenic 3D porous scaffolds, Mater. Chem. Phys. (2016). http://dx.doi. org/10.1016/j.matchemphys.2016.03.040.

[7] S. Wu, J. Wu, J.H. Yue, M.K.T. To, H.B. Pan, W.W. Lu, X.L. Zhao, Poly (D,L-lactic acid) electrospun fibers with tunable surface nanotopography for modulating drug release profiles, Mater. Lett. 161 (2015) 716-719.

[8] A.A. Sayed, 3D scaffolds of PDLLA nanofibers as carrier for growth factors for bone regeneration, J. Tissue Eng. Regen. Med. 8 (2014) 429.

[9] B. Zou, X. Chen, W. Zhi, Y.W. Liu, W.G. Cui, S.C. Hu, X.H. Li, Promoted healing of femoral defects with in situ grown fibrous composites of hydroxyapatite and poly(D,Llactide), J. Biomed. Mater. Res. A 100A (2012) 1407-1418.

[10] I.A.W.B. Siqueira, M.A.F. Corat, B.D.N. Cavalcanti, W.A.R. Neto, A.A. Martin, R.E.S Bretas, F.R. Marciano, A.O. Lobo, In vitro and in vivo studies of novel poly(D,L-lactic acid), superhydrophilic carbon nanotubes, and nanohydroxyapatite scaffolds for bone regeneration, ACS Appl. Mater. Interfaces 7 (2015) 9385-9398.

[11] L. Xiao, B. Wang, G. Yang, M. Gauthier, Poly(Lactic Acid)-Based Biomaterials: Synthesis, Modification and Applications, INTECH Open Access Publisher, 2012.

[12] M.J. Yaszemski, D.J. Trantolo, K.U. Lewandrowski, V. Hasirci, D.E. Altobelli, D.L. Wise Tissue Engineering And Novel Delivery Systems, CRC Press, 2003.

[13] N.K. Nga, T.T. Hoai, P.H. Viet, Biomimetic scaffolds based on hydroxyapatite nanorod/ poly $(\mathrm{D}, \mathrm{L})$ lactic acid with their corresponding apatite-forming capability and biocompatibility for bone-tissue engineering, Colloids Surf. B: Biointerfaces 128 (2015) 506-514.

[14] A.I. Leal, S.G. Caridade, J.L. Ma, N. Yu, M.E. Gomes, R.L. Reis, J.A. Jansen, X.F. Walboomers, J.F. Mano, Asymmetric PDLLA membranes containing Bioglass (R) for guided tissue regeneration: characterization and in vitro biological behavior, Dent. Mater. 29 (2013) 427-436.

[15] A.S. Hoffman, Surface modification of polymers: physical, chemical, mechanical and biological methods, Macromol. Symp. 101 (1996) 443-454

[16] Y. Ikada, Surface modification of polymers for medical applications, Biomaterials 15 (1994) 725-736

[17] G. Ajeesh, S. Bhowmik, S. Venugopal, L. Varshney, A. Baluch, Y. Park, S. Gilsang, C.G. Kim, Influence of chemically and plasma-functionalized carbon nanotubes on highperformance polymeric nanocomposites, High Perform. Polym. 28 (2016) 570-580.

[18] B.V.M. Rodrigues, A.S. Silva, G.F.S. Melo, L.M.R. Vasconscellos, F.R. Marciano, A.O Lobo, Influence of low contents of superhydrophilic MWCNT on the properties and cell viability of electrospun poly (butylene adipate-co-terephthalate) fibers, Mater. Sci. Eng. C 59 (2016) 782-791.

[19] B.V.M. Rodrigues, N.C. Leite, B.D.N. Cavalcanti, N.S. da Silva, F.R. Marciano, E.J. Corat T.J. Webster, A.O. Lobo, Graphene oxide/multi-walled carbon nanotubes as nanofeatured scaffolds for the assisted deposition of nanohydroxyapatite: characterization and biological evaluation, Int. J. Nanomedicine 11 (2016) 2569-2585.

[20] M.A.V.M. Grinet, H. Zanin, A.E.C. Granata, M. Porcionatto, F.R. Marciano, A.O. Lobo Fast preparation of free-standing nanohydroxyapatite-vertically aligned carbon nanotube scaffolds, J. Mater. Chem. B 2 (2014) 1196-1204.

[21] R.F. do Prado, F.S. de Oliveira, R.D. Nascimento, L.M.R. de Vasconcellos, Y.R. Carvalho, C.A.A. Cairo, Osteoblast response to porous titanium and biomimetic surface: In vitro analysis, Mater. Sci. Eng. C Mater. Biol. Appl. 52 (2015) 194-203.

[22] R. Dimitriou, G.I. Mataliotakis, G.M. Calori, P.V. Giannoudis, The role of barrier membranes for guided bone regeneration and restoration of large bone defects: current experimental and clinical evidence, BMC Med. 10 (2012) 81

[23] O. Saligheh, M. Forouharshad, R. Arasteh, R. Eslami-Farsani, R. Khajavi, B. Yadollah Roudbari, The effect of multi-walled carbon nanotubes on morphology, crystallinity and mechanical properties of PBT/MWCNT composite nanofibers, J. Polym. Res. 20 (2013) 1-6.

[24] A.O. Lobo, H. Zanin, I.A.W.B. Siqueira, N.C.S. Leite, F.R. Marciano, E.J. Corat, Effect of ultrasound irradiation on the production of nHAp/MWCNT nanocomposites, Mater. Sci. Eng. C Mater. Biol. Appl. 33 (2013) 4305-4312.

[25] A. Kolk, C. Koch, C. Haczek, B. Gansbacher, A. Stemberger, C. Plank, Copolymer protected BMP-2 gene vectors immobilized in PDLLA films on titanium implants mediate bone regeneration, Hum. Gene Ther. 20 (2009) 1498.

[26] Y.Y. Hu, J. Wang, W.L. Xing, L.Y. Cao, C.S. Liu, Surface-modified pliable PDLLA/PCL/ beta-TCP scaffolds as a promising delivery system for bone regeneration, J. Appl. Polym. Sci. 131 (2014).

[27] C.D. Hoemann, H. El-Gabalawy, M.D. McKee, In vitro osteogenesis assays: influence of the primary cell source on alkaline phosphatase activity and mineralization, Pathol. Biol. 57 (2009) 318-323.

[28] K. Werengowska-Ciecwierz, M. Wisniewski, A.P. Terzyk, K. Roszek, J. Czarnecka, P. Bolibok, G. Rychlicki, Conscious changes of carbon nanotubes cytotoxicity by manipulation with selected nanofactors, Appl. Biochem. Biotechnol. 176 (2015) 730-741.

[29] V. Forest, A. Figarol, D. Boudard, M. Cottier, P. Grosseau, J. Pourchez, Adsorption of lactate dehydrogenase enzyme on carbon nanotubes: how to get accurate results for the cytotoxicity of these nanomaterials, Langmuir 31 (2015) 3635-3643.

[30] D. Breznan, D. Das, C. MacKinnon-Roy, B. Simard, P. Kumarathasan, R. Vincent, Nonspecific interaction of carbon nanotubes with the resazurin assay reagent: impact on in vitro assessment of nanoparticle cytotoxicity, Toxicol. in Vitro 29 (2015) 142-147. 
[31] S. Arora, H. Kaur, R. Kumar, R. Kaur, D. Rana, C.S. Rayat, I. Kaur, S.K. Arora, P. Bubber, L.M. Bharadwaj, In vitro cytotoxicity of multiwalled and single-walled carbon nanotubes on human cell lines, Fullerenes, Nanotubes, Carbon Nanostruct. 23 (2015) 377-382.

[32] S. Alarifi, D. Ali, A. Verma, F.N. Almajhdi, A.A. Al-Qahtani, Single-walled carbon nanotubes induce cytotoxicity and DNA damage via reactive oxygen species in human hepatocarcinoma cells, In Vitro Cell. Dev. Biol. Anim. 50 (2014) 714-722.

[33] N. Chatterjee, H.J. Eom, J. Choi, A systems toxicology approach to the surface functionality control of graphene-cell interactions, Biomaterials 35 (2014) 1109-1127.

[34] Y.F. Li, H.Y. Yuan, A. von dem Bussche, M. Creighton, R.H. Hurt, A.B. Kane, H.J. Gao Graphene microsheets enter cells through spontaneous membrane penetration a edge asperities and corner sites, Proc. Natl. Acad. Sci. U. S. A. 110 (2013) $12295-12300$

[35] A.D. Bobadilla, E.L.G. Samuel, J.M. Tour, J.M. Seminario, Calculating the hydrodynamic volume of poly(ethylene oxylated) single-walled carbon nanotubes and hydrophilic carbon clusters, J. Phys. Chem. B 117 (2013) 343-354.

[36] R.P. Singh, M. Das, V. Thakare, S. Jain, Functionalization density dependent toxicity of oxidized multiwalled carbon nanotubes in a murine macrophage cell line, Chem. Res. Toxicol. 25 (2012) 2127-2137.

[37] V.C. Sanchez, A. Jachak, R.H. Hurt, A.B. Kane, Biological interactions of graphene-family nanomaterials: an interdisciplinary review, Chem. Res. Toxicol. 25 (2012) 15-34
[38] A.O. Lobo, E.F. Antunes, M.B. Palma, C. Pacheco-Soares, V.J. Trava-Airoldi, E.J. Corat, Monolayer formation of human osteoblastic cells on vertically aligned multiwalled carbon nanotube scaffolds, Cell Biol. Int. 34 (2010) 393-398.

[39] E. Antonioli, A.O. Lobo, M. Ferretti, M. Cohen, F.R. Marciano, E.J. Corat, V.J. TravaAiroldi, An evaluation of chondrocyte morphology and gene expression on superhydrophilic vertically-aligned multi-walled carbon nanotube films, Mater. Sci. Eng. C Mater. Biol. Appl. 33 (2013) 641-647.

[40] A.O. Lobo, M.A. Corat, S.C. Ramos, J.T. Matsushima, A.E. Granato, C. Pacheco-Soares, E.J. Corat, Fast preparation of hydroxyapatite/superhydrophilic vertically aligned multiwalled carbon nanotube composites for bioactive application, Langmuir 26 (2010) 18308-18314.

[41] M.M. Machado, A.O. Lobo, F.R. Marciano, E.J. Corat, M.A. Corat, Analysis of cellular adhesion on superhydrophobic and superhydrophilic vertically aligned carbon nanotube scaffolds, Mater. Sci. Eng. C Mater. Biol. Appl. 48 (2015) 365-371.

[42] T.C. Marsi, T.G Santos, C. Pacheco-Soares, EJ Corat, F.R. Marciano, A.O Lobo, Biomineralization of superhydrophilic vertically aligned carbon nanotubes, Langmuir 28 (2012) 4413-4424.

[43] A.O. Lobo, I.A. Siqueira, M.F. das Neves, F.R. Marciano, E.J. Corat, M.A. Corat, In vitro and in vivo studies of a novel nanohydroxyapatite/superhydrophilic vertically aligned carbon nanotube nanocomposites, J. Mater. Sci. Mater. Med. 24 (2013) 1723-1732. 